\title{
Bivalvularni infektivni endokarditis uzrokovan bakterijom Staphylococcus aureus u prethodno zdrave trudnice - prikaz slučaja
}

\author{
Bivalvular Staphylococcus aureus endocarditis in a young pregnant woman without known \\ previous risk factors - a case report

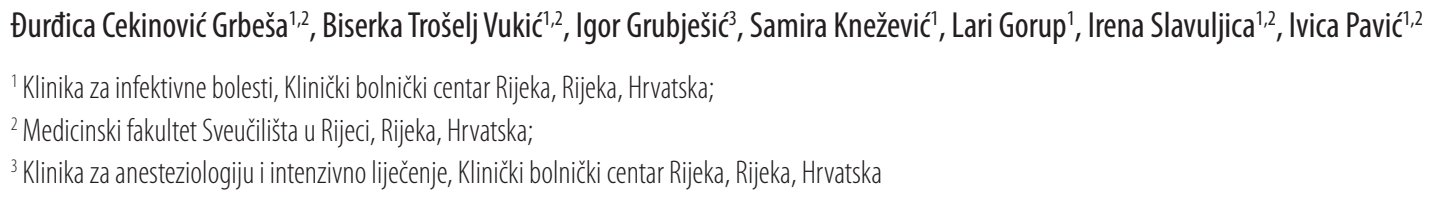

Ključne riječi:

endokarditis

stafiokok

trudnoća

Keywords:

endocarditis

staphylococcus

pregnancy

Primljeno: $15-5-2020$

Received: $15-5-2020$

Prihvaćeno: $5-7-2020$

Accepted: 5-7-2020

\section{$\checkmark$ Adresa za dopisivanje:}

doc. dr. sc. Đurđica Cekinović Grbeša, dr. med.

Klinika za infektivne bolesti, Klinički bolnički centar Rijeka

Krešimirova 42, 51000 Rijeka, Croatia

e-mail:durdica.cekinovic@uniri.hr

\begin{abstract}
Sažetak
Infektivni endokarditis značajan je uzrok pobola i smrtnosti. Posebno je težak klinički entitet u trudnica s obzirom na određeni stupanj imunosupresije u trudnoći, kao i zbog značajnih promjena kardiovaskularne funkcije u trudnica. Većina infektivnih endokarditisa, pa i u trudnoći, uzrokovana je bakterijama, a dominantno je zahvaćen jedan srčani zalistak, najučestalije mitralnog ušća. U ovom radu je prikazan slučaj liječenja i ishoda endokarditisa mitralnog i aortnog zaliska uzrokovanog bakterijom Staphylococcus aureus u prethodno zdrave trudnice.
\end{abstract}

\begin{abstract}
Infectious endocarditis is a significant cause of morbidity and mortality. It is a particularly difficult clinical entity in pregnant women due to a certain degree of immunosuppression in pregnancy, as well as due to significant changes in cardiovascular function in pregnant women. Most infectious endocarditis cases, even in pregnancy, are caused by bacteria, with one heart valve, most commonly the mitral orifice, predominantly affected. This paper presents treatment and outcome of mitral and aortic valve endocarditis caused by Staphylococcus aureus in a previously healthy pregnant woman.
\end{abstract}

\section{Uvod}

Tijekom trudnoće, velik broj organskih sustava majke prilagođava svoju funkciju u svrhu zaštite i razvoja fetusa. Periferna vazodilatacija i povećanje srčanog minutnog volumena najznačajnije su promjene u kardiovaskularnom sustavu, a supresija stanične imunosti ključna je modulacija imunološkog sustava tijekom trudnoće. Međutim, navedeni fiziološki mehanizmi izlažu trudnice brojnim infekcijama, uključujući i infektivnom endokarditisu ${ }^{[1,2]}$. Infektivni se endokarditis (IE) pojavljuje kod manje od 0,1\% trudnoća, no nosi visoku stopu rizika od smrtnosti, kako kod majke, tako i kod fetusa (stopa smrtnosti trudnica doseže i do $33 \%$, a fetusa do $29 \%)^{[3,4]}$. Popuštanje srca i embolizacija dominantni su uzroci smrtnosti kod trudnica $s$ infektivnim endokarditisom ${ }^{[5,6]}$. Endokarditis se najčešće javlja na jednom zalisku, najčešće mitralnom, a koji je prethodno oštećen ili se radi o protezi, no zahvaćenost više zalistaka u IE rijetka je pojava ${ }^{[7,8]}$. Uzročnici IE dominantno su Gram pozitivni koki, od kojih većinu slučajeva čini zlatni Stafilokok (Staphylococcus aureus). Kod trudnica su opisani i slučajevi IE uzrokovani nespecifičnim uzročnicima kao što je Bacillus cereus ili gljive (najčešće iz roda Candida) ${ }^{[9,10]}$, no tu se radilo o trudnicama s podležećom patologijom kao što su dijabetes, imunokompromitirano stanje uslijed malignih ili imunoloških bolesti ili ovisnost o opijatima. Prikazujemo slučaj mlade, prethodno zdrave trudnice s IE mitralnog i aortnog zaliska uzrokovanog bakterijom $S$. aureus.

\section{Prikaz slučaja}

Prethodno zdrava, 25-godišnja trudnica u 28. tjednu prve trudnoće javila se u Objedinjeni hitni bolnički prijem KBC Rijeka zbog febriliteta do $39,6^{\circ} \mathrm{C}$, grlobolje i eritema kože lica u trajanju od četiri dana pred 
prijem. U anamnezi je navela i mučninu i povraćanje te bolnu oteklinu lijeve pete $\mathrm{u}$ trajanju od jednog dana pred prijem. Bolesnica je pri pregledu pokazivala parametre sistemskog upalnog odgovora (engl. Systemic Inflammatory Response Syndrome; SIRS): bila je febrilna (tjelesna temperatura $38^{\circ} \mathrm{C}$ mjerena bezkontaktnim termometrom), hipotenzivna (RR 90-60 mmHg nad kubitalnom arterijom), ubrzanog srčanog pulsa (c/p 126/min) i ubrzane frekvencije disanja (RF 20/min), no uredne saturacije krvi kisikom $\left(\mathrm{sO}_{2}\right.$ mjeren pulsnim oksimetrom na periferiji iznosio je 96\%) te urednog stanja svijesti (15 na Glasgowskoj skali kome). Fizikalnim pregledom detektiran je eritematozni osip obraza i uški, pojedinačne petehije na prstima obje šake i petama te sluznici ždrijela. Također su bili uvećani i bolno osjetljivi angularni limfni čvorovi na vratu. Kod prijema, auskultacijom srca nije detektiran srčani šum. Bolesnica nije imala podležećih kroničnih bolesti niti je uzimala lijekova, negirala je recentne ozljede, kao i stomatološke zahvate. Epidemiološka anamneza nije ukazivala na kontakte s oboljelim osobama, a jedini podatak koji bi mogao biti relevantan za ovaj slučaj bio je nedavni kozmetički tretman lica, oko tjedan dana pred prijem.

Klinički i laboratorijski nalazi ukazivali su na sistemsku bakterijsku infekciju uz SIRS (Tablica 1) te je pacijentica hospitalizirana u Jedinici intenzivnog liječenja Klinike za anesteziologiju KBC Rijeka. Po uzorkovanju mikrobioloških uzoraka započeta je dvojna empirijska antimikrobna terapija vankomicinom $\mathrm{u}$ dozi 2 x 1 g i.v. i klindamicinom u dozi 3 x $900 \mathrm{mg}$ i.v. uz suportivnu terapiju. $\mathrm{U}$ tri uzastopne hemokulture, uzorkovane u razmaku od $6 \mathrm{~h}$, dokazan je meticilin-osjetljiv Staphylococcus aureus (MSSA) koji je dokazan i u urinokulturi i brisu nazofarinksa, dok je bris ždrijela ostao negativan na patogene bakterije. Po dospjeću nalaza MSSA iz prve hemokulture, vankomicin je zamijenjen ciljanim anstistafilokonim antibiotikom - flukloksacilinom u dozi 6 x 2 g i.v. (sveukupna dnevna doza od $12 \mathrm{~g}$, primjenjiva za liječenje infektivnog endokarditisa uzrokovanog MSSA), uz daljnju primjenu klindamicina. Drugog dana hospitalizacije proširena je obrada suspektnog endokarditisa te je pregledom očne pozadine dokazan korioretinitis oba oka, a ultrazvukom trbuha uvećana slezena (veličinom je mjerila $14 \times 9 \times 2 \mathrm{~cm}$ ), a tijekom sljedećih 10 dana na noktima bolesnice razvila su se splinter krvarenja te Janewayeve lezije na obje pete; prema Dukeovim kriterijima, sekundarni klinički znakovi infektivnog endokarditisa. Transtorakalnim ultrazvukom srca (TTE) učinjenim 4. i 8. dana hospitalizacije nisu dokazane vegetacije na srčanim zaliscima. Bolesnica je od 10 . dana hospitalizacije bila kardiocirkulatorno i respiratorno stabilna te je liječenje nastavljeno na odjelu intenzivne njege Klinike za infektivne bolesti KBC Rijeka. Magnetska rezonanca srca (engl. cardiac magnetic resonance; $\mathrm{CMR}$ ) učinjena je 12. dana hospitalizacije te je ista pokazala nodularno zadebljanje mitralnog za-

TABliCA 1. ReZultati laboratoriJSKiH ANALIZA NA DAN PRIJEMA I 2. DAN HOSPITALIZACIJE

TABLE 1. LABORATORY RESULTS ON DAY OF ADMISSION AND ON DAY 2 OF HOSPITALIZATION

\begin{tabular}{|c|c|c|c|}
\hline & Dan prijema & 2. dan hospitalizacije & Referentne vrijednosti \\
\hline Leukociti & 7.9 & 19,9 & $3.4-9.7 \times 10^{9} / \mathrm{L}$ \\
\hline Eritrociti & 2.88 & 2,30 & $3.86-5.08 \times 10^{12} / \mathrm{L}$ \\
\hline Hemoglobin & 88 & 68 & $119-157 \mathrm{~g} / \mathrm{L}$ \\
\hline Hematokrit & 0,26 & 0,21 & $0.356-0.470 \mathrm{~L} / \mathrm{L}$ \\
\hline Trombociti & 124 & 61 & $158-424 \times 10^{9} / \mathrm{L}$ \\
\hline CRP & 373.7 & 370 & $0-5 \mathrm{mg} / \mathrm{L}$ \\
\hline Laktat & 13.0 & 12,5 & $0.5-2.2 \mathrm{mmol} / \mathrm{L}$ \\
\hline Prokalcitonin & 10.7 & 10,89 & $<0.5 \mathrm{ng} / \mathrm{mL}$ \\
\hline Kreatinin & 119 & 133 & 49-90 umol/L \\
\hline Natrij & 131 & 133 & $137-146 \mathrm{mmol} / \mathrm{L}$ \\
\hline Kalij & 3.0 & 3.1 & $3.9-5.1 \mathrm{mmol} / \mathrm{L}$ \\
\hline Kalcij & 2,06 & 1,81 & $2.14-2.53 \mathrm{mmol} / \mathrm{L}$ \\
\hline Bilirubin & 36 & 28 & 3-20 umol/L \\
\hline AST & 144 & 158 & $8-30 \mathrm{U} / \mathrm{L}$ \\
\hline ALT & 114 & 140 & $10-36 \mathrm{U} / \mathrm{L}$ \\
\hline
\end{tabular}


liska (Slika 1.), a transezofagealnim ultrazvukom srca (TEE) 14. dana hospitalizacije dokazane su vegetacije mitralnog i aortalnog zaliska; čime je definitivno dokazan infektivni endokarditis. Važno je dodati kako su na učinjenoj CMR dokazani intrapulmonalni infiltrat donjeg režnja lijevog pluća i obostrani pleuralni izljevi, dok je magnetska rezonanca mozga bila uredna; bez znakova tromboembolizacija.

Slika 1. Magnetska ReZonanCa SRCA UČInJena JE NA UREĐAju 1,5 T (Siemens Medical Systems, Erlangen, NjemačKa). STRELICA POKAZUJE NODULARNO ZADEBLJANJE STRAŽNJEG LISTA MITRALNOG ZALISKA.

Figure 1. Cardiac Magnetic Resonance Imaging (CMR) WAS PERformed USing 1,5 T sCanner (Siemens Medical SysTems, Erlangen, Germany). The arrow points to nodular THICKNESS OF THE POSTERIOR MITRAL CUSPIS.

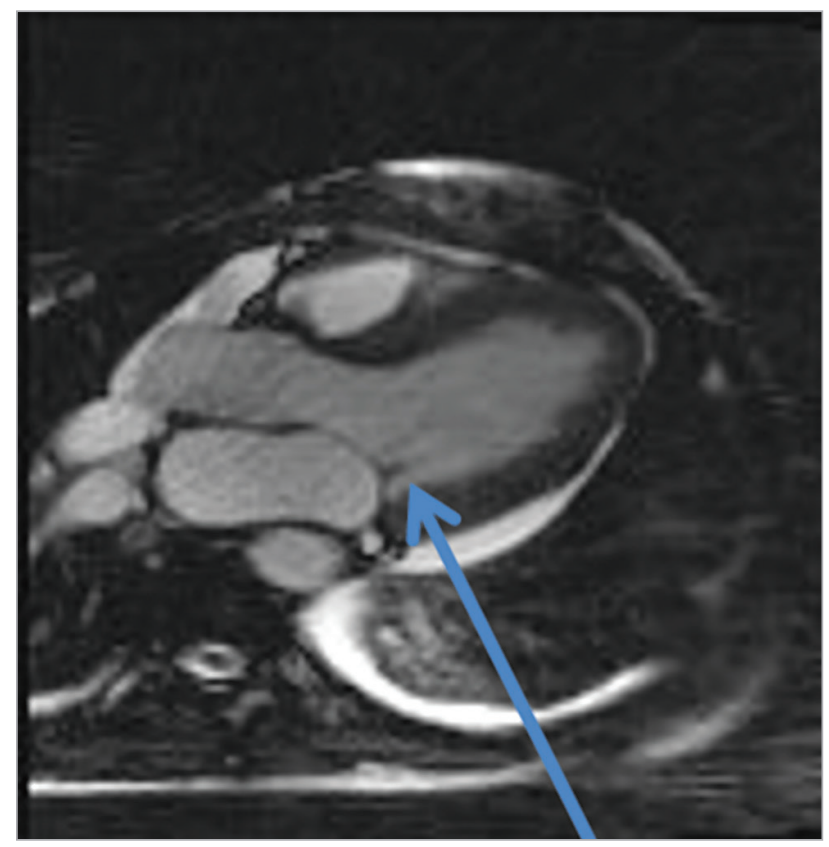

Bolesnica je sveukupno antimikrobno liječena flukloksacilinom tijekom šest tjedana (klindamicin je ukinut nakon dva tjedna davanja) uz suportivnu terapiju (prevencija troboemboličkih incidenata subkutanim injekcijama niskomolekularnog heparina, prevencija sluzničnog ulkusa inhibitorima protonske pumpe, korekcija anemije koncentratima eritrocita, parenteralna nadoknada elektrolita i tekućine, potporno liječenje kisikom na masku prema vrijednostima $\mathrm{sO}_{2} \mathrm{u} \mathrm{krvi}$ ). Kontrolne su hemokulture bile sterilne od trećeg dana ciljane antimikrobne terapije, a kliničko se stanje bolesnice postupno popravljalo (povremeno je bila tahipnoična i tahikardna, no urednih vrijednosti krvnog tlaka i kardiocirkulatorno stabilna). Tijekom hospitalizacije višestruko je pregledavana od strane ginekologa obstetričara; na svim ultrazvučnim pre- gledima ustanovljeni su uredan fetalni prirast, uredan indeks amnijske tekućine i uredan protok krvi u pupčanim arterijama.

Kao posljedica svega navedenoga, na temelju konzilijarnih odluka specijalista infektologa, specijalista intenzivnog liječenja, kardiologa, kardijalnog kirurga i ginekologa obstetričara, provedeno je konzervativno liječenje IE uzrokovanog MSSA u trudnice. Po završenom liječenju, TTE je pokazao uredan valvularni aparat. Šest tjedana po završetku liječenja, trudnoća je završena rođenjem zdravog ženskog novorođenčeta. Kontrolni je TTE učinjen šest mjeseci nakon liječenja te je isti, također, bio uredan.

\section{Rasprava i zaključci}

Bolesti srca kod trudnica vodeće su bolesti trudnica, nevezane uz trudnoću ${ }^{[11]}$. Infektivni endokarditis, iako rijetke pojavnosti, životno je ugrožavajuća bolest kod svih bolesnika, a većinom se javlja kod osoba, pa i trudnica, s anamnezom prethodnih bolesti srca (urođene srčane mane, reumatske bolesti srca, umjetni srčani zalisci) ili intravenskih ovisnika ${ }^{[6-8]}$. U ovom smo radu prikazali slučaj prethodno zdrave trudnice s IE mitralnog i aortnog zaliska uzrokovanog MSSA. Patogeneza IE ne razlikuje se kod trudnica u odnosu na ostale oboljele, no etiologija da: sustavnim pregledom literature razvidno je kako su bakterije iz skupine Streptokoka primarni uzročnici endokardisa kod trudnica i babinjača u ranom postnatalnom periodu, a najčešći rizični čimbenik recentni stomatološki zahvat ${ }^{[6]}$. U ovom je slučaju, kao uzročnik endokarditisa, dokazan MSSA, vodeći uzročnik endokarditisa u općoj populaciji. Pretpostavljamo kako je nedavni nesterilni kozmetički tretman akni na licu bio uzrok ulaska MSSA u sistemsku cirkulaciju i posljedičnog razvoja IE.

Antimikrobno je liječenje IE kod trudnica jednako kao i u drugim skupinama bolesnica, no dvije trećine trudnica s IE zahtijevaju kardiokirurško liječenje ${ }^{[5]} \mathrm{s}$ ciljem zamjene zahvaćenog zaliska. Fetalna smrtnost kod trudnica, kod kojih je neophodan kardiokirurški zahvat, najviša je u prvoj polovici trudnoće. Dapače, kardiokirurški se zahvat nastoji odgoditi do 28. tjedna trudnoće $e^{[5]}$. Upravo u ovom slučaju trudnice s IE u 28. tjednu trudnoće, pravovremeno primijenjena ciljana antimikrobna terapija uz mjere intenzivnog liječenja bila je prvi odabir za liječenje IE. Važno je naglasiti kako je vankomicin pravovremeno zamijenjen flukloksacilinom, budući da vankomicin u liječenju IE uzrokovanog MSSA ima sporije baktericidno djelovanje u odnosu na kloksacilin ${ }^{[2]}$ te je dokazana viša smrtnost kod bolesnika s IE uzrokovanog MSSA liječenih vankomicinom u odnosu na one liječene kloksa- 
cilinom $^{[13]}$. Također, vankomicin se povezuje s provodnim gubitkom sluha i toksičnim oštećenjem bubrega fetusa kod trudnica liječenih vankomicinom u 2. i 3. trimestru trudnoće.

Najčešća je komplikacija IE kongestivno zatajenje srca, a javlja se kod više od polovice oboljelih. Također se nalaze apscesi, embolusi, fistule i pseudoaneurizme $\operatorname{srca}^{[14]}$, a navedena stanja čine četvrtinu (25\%) indikacija kardiokirurških zahvata ${ }^{[14]}$. U ovome je slučaju konzervativno antimikrobno liječenje IE bilo uspješno.

Zaključno, IE kod trudnica predstavlja životno ugrožavajuće stanje, kako majke, tako i fetusa, a pravovremena dijagnoza i interdisciplinarni pristup neophodni su za povoljan ishod liječenja.

\section{LITERATURA}

[1] Sanghavi M, Rutherford JD. Cardiovascular physiology of pregnancy. Circulation. 2014;130(12):1003-8.

${ }^{[2]}$ Bonney EA. Immune Regulation in Pregnancy: A Matter of Perspective? Obstet Gynecol Clin North Am. 2016;43(4):679-98.

${ }^{[3]}$ Habib G, Lancellotti P, Antunes MJ, Bongiorni MG, Casalta JP, Del Zotti F, et al. 2015 ESC Guidelines for the management of infective endocarditis: The Task Force for the Management of Infective Endocarditis of the European Society of Cardiology (ESC). Endorsed by: European Association for Cardio-Thoracic Surgery (EACTS), the European Association of Nuclear Medicine (EANM). Eur Heart J. 2015;36(44):3075-128.

${ }^{[4]}$ Montoya ME, Karnath BM, Ahmad M. Endocarditis during pregnancy. South Med J. 2003;96(11):1156-7.
${ }^{[5]}$ Yuan SM. Infective Endocarditis during pregnancy. J Coll Physicians Surg Pak. 2015;25(2):134-9.

${ }^{[6]}$ Kebed KY, Bishu K, Al Adham RI, Baddour LM, Connolly HM, Sohail MR, et al. Pregnancy and postpartum infective endocarditis: a systematic review. Mayo Clin Proc. 2014;89(8):1143-52.

${ }^{[7]}$ Long B, Koyfman A. Infectious endocarditis: An update for emergency clinicians. Am J Emerg Med. 2018;36(9):1686-92.

${ }^{[8]}$ Holland TL, Baddour LM, Bayer AS, Hoen B, Miro JM, Fowler VG. Infective endocarditis. Nat Rev Dis Primers. 2016;2:16059.

${ }^{[9]}$ Shah M, Patnaik S, Wongrakpanich S, Alhamshari Y, Alnabelsi T. Infective endocarditis due to Bacillus cereus in a pregnant female: A case report and literature review. IDCases. 2015; 2(4):120-3.

${ }^{[10]}$ Vaideeswar P, Shah R. Zygomycotic infective endocarditis in pregnancy. Cardiovasc Pathol. 2017;28:28-30.

${ }^{[11]}$ Seeland U, Bauersachs J, Roos-Hesselink J, Regitz-Zagrosek V. [Update of the ESC guidelines 2018 on cardiovascular diseases during pregnancy: Most important facts]. Herz. 2018; 43(8):710-8.

${ }^{[12]}$ Fernández Guerrero ML, de Górgolas M. Comparative activity of cloxacillin and vancomycin against methicillin-susceptible Staphylococcus aureus experimental endocarditis. J Antimicrob Chemother. 2006;58(5):1066-9.

${ }^{[13]}$ Lodise TP, McKinnon PS, Levine DP, Rybak MJ. Impact of empirical-therapy selection on outcomes of intravenous drug users with infective endocarditis caused by methicillin-susceptible Staphylococcus aureus. Antimicrob Agents Chemother. 2007;51(10):3731-3.

${ }^{[14]}$ Connolly C, O'Donoghue K, Doran H, McCarthy FP. Infective endocarditis in pregnancy: Case report and review of the literature. Obstet Med. 2015;8(2):102-4. 